\title{
The Right connections: Acknowledging epistemic progression in talk
}

\author{
R O D G A R N E R \\ Linguistics \\ School of Education and Professional Studies \\ Griffith University \\ Mounth Gravatt Campus \\ 170 Kessels Road \\ Nathan III, Australia \\ r.gardner@griffith.edu.au
}

A B S T R AC T

It is proposed that the response token Right, in one important use, is a marker of epistemic dependency between two units of talk by a prior speaker, and that this talk has progressed the understanding by the Right producer of a complex activity involving much information transfer. Two other Rights as response tokens are considered: as an epistemic confirmation token similar to That's right, and as a change-of-activity token similar to Alright/Okay. In addition, Right is shown to be different from other response tokens, including the news receipt $O h$, newsmarkers such as Really?, and continuers and acknowledgment tokens such as $\mathrm{Mm} \mathrm{hm}$ and Yeah. The primary data consist of a fully transcribed dietetic consultation in an Australian hospital between a dietician and a client. (Response tokens, listener, talk-in-interaction, epistemic token, medical discourse. $)^{1}$

I N T R O D U C T I O N

When someone is talking, listeners need to respond to the stream of talk that is emerging. They can respond in a range of ways. With Right, they may be confirming the correctness of the talk to which they are responding, in which case the Right producer has epistemic priority and thus the right to confirm something stated by the other. In another use, particularly common in Australian and British English, but on the evidence to hand much less so in North America, a speaker can tell prior speaker that he recognizes that what has just been said is designedly linked to something that had been said elsewhere: this Right acknowledges epistemic dependency between utterances. Right has received little attention (but see Stenström 1987, Gardner 2001, McCarthy 2003). It is, in this use, a claim on the part of a participant in a conversation who is currently in a listener role that what this token is responding to does not stand simply as a next action in the conversation, nor as a unit of talk that is merely progressing the interaction with a relevant next. What it is doing is recognizing that what has just 
been said is building upon, or dependent upon, something that had been said earlier, most commonly in the last but one utterance, sometimes from earlier in the conversation, or occasionally even in a previous conversation. In this sense, such Rights mark a progression of the epistemic store that is being built by the participants in the talk. They occur in a range of environments, but on the evidence of the data that have been analyzed for this article, they most typically occur during complex multi-unit turns in which a main speaker is engaged in passing on information of some kind - for example, explaining something, or providing extended advice, activities that involve the kinds of complex epistemic relationships that a recipient uses this Right to acknowledge.

Right is in a sense like many other "discourse markers," and in some ways apparently different from most of the core response tokens, in that it has an obvious lexical meaning - in fact, a wide range of lexical meanings. In one of its most frequent meanings, it is epistemic, with the sense of 'correct'. It is probable that Right as a response token has evolved from this basic meaning, at least in British and Australian English, but to a lesser extent American English, not only to confirming the epistemic correctness of a prior utterance, but to claiming recognition of the epistemic connectivity between the immediately prior utterance and some earlier utterance. It would thus seem that there has been an evolution, comparable in some respects to the evolution of Indeed, In fact, or Actually (cf. Traugott \& Dasher 2002), from a literal to a discourse functional meaning. In the case of Right, this has perhaps been from an utterance-internal adverb or adjective meaning 'correct', to a speaker's check whether the recipient has understood (an utterance-terminal rising Right), then, in a major shift, crossing over from speaker to listener, first to one who has some kind of epistemic priority and is able to confirm the correctness of prior utterance, and finally to the responsive Right where the listener has no necessary epistemic priority but claims recognition of the epistemic connectivity between two utterances being produced by the main speaker. As is to be expected with a token that has evolved in this way, there are cases where there is some ambiguity as to which use of Right is occurring, particularly between the epistemic confirmation and epistemic dependency uses (cf. Maschler's 2002 finding on the Hebrew discourse particle $k e$ 'ilu). To claim this grammaticalization process for Right, of course, is speculative, and the purpose of this article is not to trace the diachronic emergence of Right as a response token, but to examine the environment of its current use - in this instance, in a dietetic consultation at an Australian hospital.

Response tokens are little conversational objects produced by a listener, most commonly during a primary speaker's extended turn at talk. They do not of themselves add in any direct way to the topical development of the talk, ${ }^{2}$ but together with other short responses such as assessments, they reveal much about the development of intersubjectivity in talk. It has been increasingly discovered in research over the past 25 years or so that they provide parties in a conversation with a complex range of information about the stance of those who are currently 
in a role of recipient with regard to the information and actions that emerge through the talk. As Heritage 1984 noted over 20 years ago, at a time when there had been little work on response tokens,

[a]lthough it has been almost traditional to treat "oh" and related utterances (such as "yes," "uh huh," "mm hm," etc.) as an undifferentiated collection of "back channels" or "signals of continued attention," the observations presented in this chapter suggest that such treatments seriously underestimate the diversity and complexity of the tasks that these objects are used to accomplish. (1984:335).

Research on response tokens in the years since has shown him to be right (e.g. Bublitz 1989; Beach 1993; Drummond \& Hopper 1993; Jefferson 1993, 2002; Clancy et al. 1996; Sorjonen 1996; Guthrie 1997; Heritage 1998; Gardner 2001). These response tokens can provide a source of information for participants about the way the talk is developing and the trajectory it is taking. They are little nodes in the conversation, places of intersection for the emerging substantial (topical and actional) talk, making perceptible what may otherwise be hidden about how a current listener is monitoring the talk.

In the growing published work on response tokens such as Yeah, Mm hm/Uh huh, Mm, Oh, Okay, and Alright, it has emerged that each is used in a distinctive way. However, they also all have much in common. They can stand alone in a speaker's turn (though some, such as $\mathrm{Oh}$, do so relatively rarely), and as such can constitute some of the shortest turns in talk. They are all responses to an utterance by another speaker, though some, including Right, can be used in talk that is not primarily responsive. In such cases they are not response tokens. They all lack denotative meaning in the conventional sense: Their meaning derives to a very high degree from the context of the emerging talk and from the contiguous actions being performed. They all show in some way the stance that a participant is taking to the talk to which she is responding, usually the immediately prior talk. Their significance in any instance of use is also contingent upon their position in a sequence of talk (including their timing), on whether they are the only talk in their turn, and on their prosodic features, especially pitch and intonation contour (cf. Müller 1996, Gardner 2001). They all also appear to have a core use, with a typical prosodic shape - one way in which they can be seen to differ from one another. The continuers $M m ~ h m$ and $U h h u h$, for example, typically have a slightly rising terminal pitch contour and are used to pass up an opportunity for their speaker to take a full turn at talk. They are used to show that their speaker understands that some talk "is in progress but is not yet complete" (Schegloff 1993), and, because of the absence of repair, that there is no current problem in the talk for the speakers (Schegloff 1982). Yeah and Mm typically have a falling contour. In contrast to $\mathrm{Mm} \mathrm{hm}$ and $\mathrm{Uh} h \mathrm{~h} h$, they are more retrospective than prospective, acknowledging the talk to which they are responding. $M m$ is normally a weaker, less involved token than Yeah. It occurs much 
more frequently as the only talk in its turn than Yeah does, and it shows less speakership incipiency (Jefferson 1984, 1993; Gardner 1997).

$\mathrm{Oh}$, typically with a falling intonation contour, marks the prior talk as in some sense new - for example, that there has been for its speaker some kind of "change in his or her locally current state of knowledge or information" (Heritage 1984:299); in another environment this "change of state" can be a marked shift in attention in a preface to a response (Heritage 1998); or it can be a response to an assessment: $O h$ can claim a shift in orientation by its speaker to the matter being assessed to show an independent position on the question (Heritage 2002). Okay is a token that signals some degree of shift in topic or activity, as "prefigurings of movements toward next matters" (Beach 1993:341). It proposes a readiness to move out of the current topic or activity into another, or indeed out of the conversation altogether (see also Schegloff \& Sacks 1973). Alright is similar, but Beach proposes the possibility that Alright may be used to mark a more major transition. For example, in his medical data, he finds Okay used to treat the prior response as adequate, and thus closing the immediate question-answer sequence, and a subsequent Alright being used to close the more encompassing activity, namely the whole phase of diagnostic medical history (see also Turner 1999). ${ }^{3}$

The main data set for this study is a 47-minute consultation in an Australian hospital between a dietician and a "client" (patient) with high blood triglyceride levels. This was video- and audiotaped. The main purpose of such interviews is usually twofold (cf. Tapsell 1997): to gather information about the dietary habits of the patient, and to provide information and advice that is intended to encourage patients to change their eating patterns, in this case through reducing fat, sugar, and alcohol intake. The main interview used for this study was fully transcribed; it was the first meeting between the client and dietician, so there had been no discourse history between the two prior to this encounter, and no previous opportunity for them to establish common ground. In the consultation, after greetings and agreeing on the reasons for their meeting, there is a long information-gathering phase in which the dietician elicits from the patient his general state of health and quotidian dietary habits. This is followed by a phase during which she explains some basic medical information relating to his condition, particularly about cholesterol and triglycerides, and also about major food groups and healthy diets. Next there is a lengthy advice-giving phase in which she makes recommendations about how he might change his diet. Finally, they arrange a future appointment.

In such consultations, most clients would come with some considerable lay knowledge of nutrition. Diet is newsworthy, and most would have some idea about what constitutes a healthy diet, or the dangers of high cholesterol levels. One task for the dietician and client is to work out how much the latter knows. They have limited time - about an hour - and much to cover, gathering informa- 
tion about his eating habits, informing him of his condition, and providing advice and information about healthy eating to reduce his triglyceride levels. Response tokens facilitate this activity as indices of the stance the recipient of the talk is taking (cf. Gardner 2001), and this has the potential to cut down immensely the amount of time spent on informing or questioning that needs to occur to establish his prior knowledge. In particular (but not exclusively) it is the epistemic response tokens, such as Oh, I see, Right, and That's right, that achieve this in the consultation, but the more neutral continuers and acknowledgment tokens $\mathrm{Mm} \mathrm{hm,} \mathrm{Mm}$, and Yeah do so to some extent too. So as this is their first meeting, they will need to establish a shared epistemic store: their common ground, so that she can get an idea of what he knows, and what she needs to tell him or advise him. This is where, I argue in this essay, Right and the other tokens play a crucial role.

The reason for the large number of response tokens in interactions such as this is, at least in part, the great amount of information transfer between the speakers: The client tells the dietician about his dietary habits, and the dietician informs and advises the client about matters to do with his diet and nutrition. Among the response tokens found in this consultation there were about 110 Rights. The core interview data have been supplemented with a second dietetic interview from the same Australian hospital, as well as with conversational and medical data from the United States, and conversational data from Britain and Australia, both face-to-face and telephone: 65 from Australian conversations, 84 from British conversations, and about 50 from U.S. conversations. ${ }^{4}$

\section{IN ITIAL CHARACTERIZATION OF RIGHT AS A RESPONSE TOKEN}

Among the few articles in which Right is discussed, McCarthy 2003 talks about three occurrences of Right in a short fragment and suggests that two "seem to be confirming receipt of the information" (44) - thereby not really distinguishing them from other acknowledgment tokens - and the third "seems to be performing a more global function of signaling ... a desired (pre-)closure" (45), which is similar to the "change-of-activity" type of Right discussed below. Stenström 1987, using a Birmingham Discourse Analysis framework, surveys Right, Alright, That's right, Righto, That's alright, and It's alright. She proposes inter alia that Alright seems to be saying 'let's move on', while Right seems to be saying 'let's leave this' (96-97), which she puts in another way as Right being a "switchoff signal" and Alright a "switch-on signal" (98). She also suggests that turninitial Rights (and others from the related group she is investigating) can realize accepts, agreements, "smoothers," and confirms, depending on what they are responding to - for example, requests, directs, suggests, apologies, or elicits. In seeking an explanation for the range of realizations, she assumes that "they differ in degree of emphasis and involvement, in that Right is weaker than That's 
right and both reflect less involvement than All right" (104), but no real attempt is made to establish what distinguishes the Right family of responses from other response tokens.

Heritage \& Sefi 1992, in an article on health visitor-first-time mother interactions in the United Kingdom, gloss Right in a mother's response to some advice from a health visitor as "overtly marking its acceptance" (391). Further, in a footnote they claim that "a mother's additional use of 'right' to acknowledge acceptance of advice after her acceptance has been resolicited is further evidence that 'right' is a standard, but 'minimal' form of marked acknowledgement for the acceptance of advice" (416), but the claim is not supported by detailed argument. Indeed, in an examination of the examples they provide, these Rights occur after talk in which a dependency relationship has been expressed. For example, in one of the instances referred to in the above quotes, a Right occurs in response to if you're not breast feeding there's no reason why you shouldn't start them [contraceptive pills] when she's four week. = On the day she's four weeks you can: (391). There is a complex dependency here of condition: If $\mathrm{X}$ isn't happening, you can do $\mathrm{Y}$ at time Z. This is precisely the kind of dependency to which Right responds, as shown in the analyses below.

As alluded to above, one respect in which Right is different from the response tokens glossed above (with the exception of Alright) is that, as a lexical item, it has a richer semantic content - it is a word with 53 entries in the Shorter Oxford English Dictionary, and it is one of the major meanings, that something is 'correct' or 'true', that is in fact close to one of its uses as a response token, especially in the American English data that have been examined for this article. In American English, this epistemic confirmation use, with affinities to That's right, appears to be the major one as a response token. This use is seen in excerpt (1), which is from an American dinner conversation:

(1) R-9-US-Chinese Dinner ${ }^{5}$

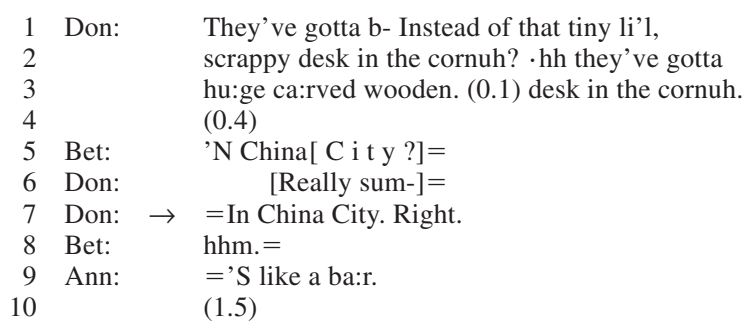

Here Don's Right in line 7, following as it does his repetition of in China City, confirms that Betty's query as to whether the location in question is China City is correct, or 'right'. As a confirmation of Beth's candidate clarification, this Right also asserts Don's epistemic priority over this information: He has the principal knowledge of the location, or the "epistemic independence," as he is the 
one who is relating the story. Don has "primary access," and "knows better" about the location (cf. Heritage 2002).

Right is also used at times as what appears to be a truncated version of Alright, a token most typically used in environments in which participants are moving from one topic or activity toward another, particularly when the boundary is major (cf. Beach 1993, Turner 1999, Gardner 2001). Alright is in many ways similar to Okay as a response token, though the former is found more at major topic changes, at major activity shifts, and as the final pre-closing token in an interaction. The following extract, from Australian conversational data, is an example of Right used in a typical Alright environment. Ron proposes moving the conversation from talking about their son taking a shower to a non-talk activity, chopping wood:

(2) $R+S S S T \cdot 17 . R \& S B 3 b$

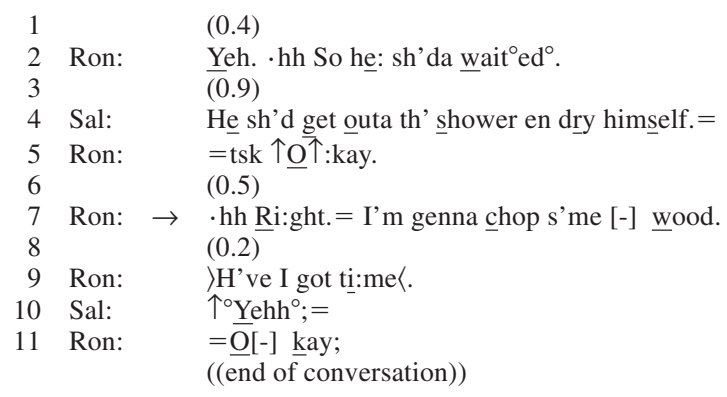

The Right in line 7 (together with the Okay in line 5) proposes a transition from the ongoing talk toward a closing of the conversation (cf. Schegloff \& Sacks 1973). What this token flags is a proposed change-of-activity, and indeed, after a further brief sequence, the conversation does end.

While some Rights are demonstrably variants of, or at least have close affinity to, That's right (as in extract 1) and Alright (as in extract 2), many Rights in British and Australian English (and on the evidence to hand, at least occasionally in U.S. English) are different, what I will be calling an EPISTEMIC DEPENDENCY MARKER. For an initial characterization of this kind of Right, consider the following extract, which is from near the end of the dietetic consultation. An initial observation is that, ethnographically speaking, this consultation is an example of an expert-lay interaction, the point of which is to provide the client with information that he does not have, so that he can adopt a healthier lifestyle. Informings are built to be news (Goodwin 1979, Maynard 2003). This is, of course, not to deny that the client would bring some knowledge to the meeting, and there are indeed places where he shows that he does know something about dietary fats and healthy eating.

The dietician is going through an information sheet about low-fat foods that she is about to give to the client to take home. As she does so, client produces two Rights: 
(3) JD21:CT9:44'07":20316

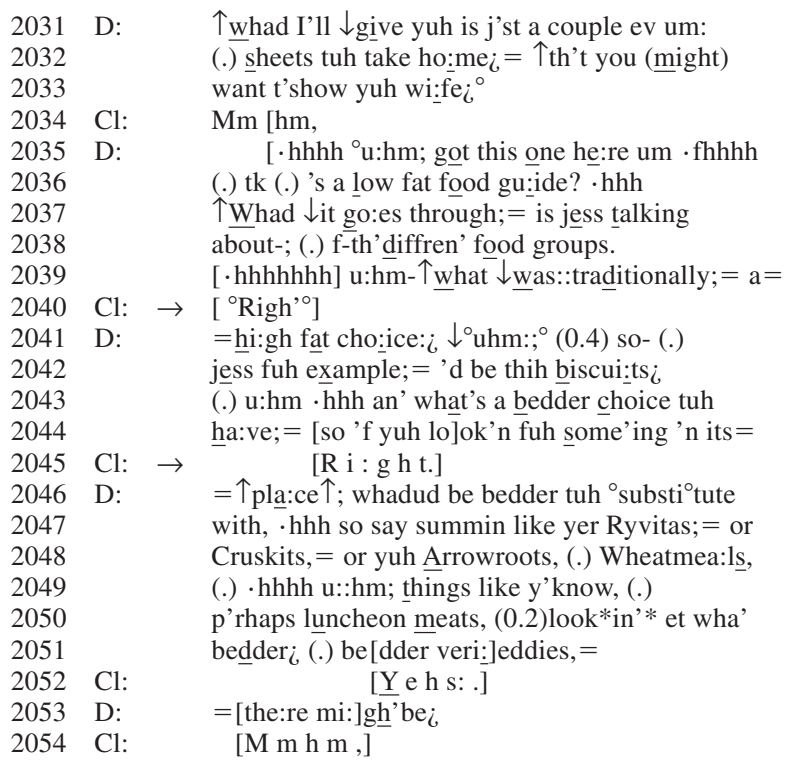

To establish what these Rights are doing, what I am calling the marking of epistemic dependency (and the epistemic progression toward understanding a relationship between two bits of information), it helps to show what they are NOT doing, by comparing them with other tokens that could conceivably occur in this position, and indeed are found in this consultation, such as $\mathrm{Oh}$ or I see (as change-of-state tokens or markers of understanding), That's right, (epistemic confirmation tokens), Alright or Okay (change-of-activity tokens), or Yeah or $\mathrm{Mm}$ $\mathrm{hm}$ (continuers and acknowledgment tokens). What makes the task particularly tricky is that I am proposing that the two other variants of Right are kinds of epistemic confirmation tokens and change-of-activity tokens, and these, too, have to be distinguished from the epistemic dependency Right.

The first point to note is that the dietician is engaging in an extended informing (or reporting, paraphrasing, and summarizing) of the contents of the sheet. At the beginning of this extract, the dietician picks up the information sheet and holds it between the two of them so that they can both see it. In lines 2035-8 she produces a multi-unit turn, which comes in two main parts. In the first of these she holds up (got this one here) one of these sheets and identifies it as a low fat food guide. There is no acknowledgment of this unit of talk, vocal or visual (the client is looking at the sheet). She then goes on to specify the contents of the sheet (what it goes through is just talking about $f$ - the different food groups). She shoots a glance at the client just before she finishes this unit, which elicits a Right. Based on the visual evidence from the video, it is clear that the informing is not complete at this point. Both are sitting forward and looking at the sheet, 
and the dietician is using a pencil to point to various places on the sheet. There is no indication that, for example, she is simply going to hand him the sheet at this moment to take away, and every indication that she is going to continue informing him of what is in the sheet. The client's posture indicates that he is aligned to a continuation - he remains in position.

The first question is whether this Right could be a kind of newsmarker or news receipt. As Heritage says, "Oh receipts (1) occur in response to complete chunks of information and (2) are produced at points at which the informings are possible complete" (Heritage 1984:301), and also “ 'oh' is a STRONG indication that its producer has been informed as a result of a prior turn's talk" (305). Rights such as this one, in contrast, regularly come during an extended sequence of talk by one speaker, at points where the telling is incomplete. The information may or may not be new, though in the context of the current talk it is adding something locally new. In contrast to Oh, Right is not foregrounding the prior turn's talk but is treating it as "business as usual" in the telling, but in contrast to continuers or acknowledgment tokens, it is claiming to recognize the local relevance and fit of the talk in terms of its informativeness within a larger informationloaded activity.

Right as an epistemic dependency marker is also more neutral than a news token/newsmarker or an epistemic confirmation marker in terms of the epistemic rights that a speaker claims (cf. Heritage \& Raymond 2005), which, respectively, claim no prior rights or full prior rights.

Further, Right is not responsive to news as such, nor to announcements (cf. Maynard 1997). These actions attract news receipts such as Oh (cf. Heritage 1984) or newsmarkers such as Really? or (Oh) did you? (cf. Jefferson 1984), or assessments (How terrible, How awful). In these environments, Right simply does not occur. There are, for instance, very few Rights in all the data extracts in Maynard's (2003) book Bad news, good news, ${ }^{7}$ which is about (assessable) news, and which has British and American data. This is because Right responds not to complete chunks of news but to a progressively emerging epistemic construct.

The next question is whether this Right is an epistemic confirmation markerthat is, a shortened That's right. First, it can be noted that the client does not respond with a Right after the identification/naming (got this one here, it's a low fat food guide), where epistemic confirmation might make sense if, for example, he could read the name of the sheet that the dietician is holding. The Right comes after the second unit of talk, in which she informs him of the contents of the sheet. Informings are designed to present NEW information (Goodwin 1979), so a designed-for response would be some kind of acknowledgment of the information as new (e.g. Oh, I see, or perhaps a simple continuer $\mathrm{Mm} \mathrm{hm}$ ), but not a claim of prior knowledge, which Right as epistemic confirmation would be doing; and in particular, if it were a dispreferred response negating the designedfor newness of the information, one would expect some extra work, such as an account of having seen the sheet before. What we get here is a response that is 
simple, immediate, and lacking in any account (cf. the discussion on dispreferred responses in Schegloff 2007).

What is more, in this fragment she goes on beyond the client's first Right to supply more information over a series of turns on the contents of the sheet, displaying that she does not treat it as a claim to knowledge of the sheet's contents, and the client continues to receive this information simply, immediately, and without expansions.

The use of Right as a change-of-activity token, similar to Okay or Alright, would also sit ill at this point in the sequence. The dietician has just embarked on an explanation of the guide sheet and has done no more than give an initial characterization of it. She has not said anything about what is in it, except in very general terms. As noted above, she goes on, over a number of turns, to inform him in some detail of the content of the sheet. She does not treat his Right, in other words, as proposing topic closure (which a change-of-activity token would be proposing), or as prefiguring a move to some other matter (cf. Beach 1993); instead, she goes straight on to expand on the topic in a multi-unit turn. Neither does the client do anything to indicate that he had meant this Right as a proposal to move on.

An alternative account can, however, be made of what this Right is doing. There are here two "chunks" of talk that are in a relationship of close dependence to each other. The Right at line 2040 is soft and prosodically flat, placed immediately after groups, at a point of possible TCU completion. It responds to an informing: that she has a sheet, the sheet she then identifies as a low fat food guide, and then she informs him of its contents: what it goes through is just talking about the different food groups. At the rhetorical level, the first utterance topicalizes the sheet in her hand, the next identifies it by naming it, and the third specifies, in general terms, the contents of the sheet. What I am proposing is that this relational link of specification (first identifying the sheet, then specifying the general nature of the contents of the sheet) is what this Right is acknowledging, and this progresses the higher-level action of informing him of the contents of the sheet. Their shared epistemic store has been moved forward.

The second Right in this sequence, in line 2045, is responsive to the continuing multi-unit informing. The dietician has continued by a further specification of a part of the contents of the sheet, what was traditionally a high fat choice. She next provides an example of a high-fat choice, biscuits (cookies), and then a contrast, and what's a better choice to have. So there is epistemic dependency again, in that she topicalizes high-fat foods, exemplifies this with biscuits, and contrasts this with a better choice. Their shared epistemic store has moved on again. As with the previous Right in this excerpt, it can be argued that it would be highly unlikely that this Right is an epistemic confirmation, and for similar reasons. She is continuing to present information from the sheet, which is almost 
certainly new to him, and with which she will be very familiar. It would seem highly implausible that he would be in a position to confirm the contents of a sheet that she knows and he doesn't. Furthermore, one would expect some kind of hitch somewhere in the immediately subsequent talk, were it a (dispreferred) epistemic confirmation. In fact, she again does not treat his Right as such, as she continues with further informings on the content of the sheet - examples of alternatives to biscuits - and he continues as recipient. She goes on to provide another example of a high-fat food, luncheon meats, and this time the client responds recognitionally (cf. Jefferson 1983), but with Yes and Mm hm. In other words, the dietician has continued with her series of informings about the content of the information sheet, and this time he has responded not with an epistemic dependency marker but with an archetypical acknowledgment token and a continuer. So the client has responded to very similar actions by the dietician in this sequence of sequences (cf. Schegloff 2007), in a multi-unit turn of informings about one object, with two Rights, a Yes, and an $\mathrm{Mm} \mathrm{hm}$. Suffice it to say at this point that this Yes and $\mathrm{Mm} \mathrm{hm}$ come after a SECOND characterization of the sheet contrasting high-fat foods and better alternatives; thus there has been no significant progression of the epistemic store.

Another point is that this second Right does not come at a point of moving on to another activity: There is an even stronger sense of pragmatic incompletion here (cf. Ford \& Thompson 1996), as the dietician has mentioned a better choice but not mentioned what it is, and she goes on to mention a number of them. So the evidence is that this is not a change-of-activity token.

Rights are not the only response tokens that occur following units of talk that at least appear to progress the epistemic store. The most frequently found alternative in these environments is the continuer $\mathrm{Mm} \mathrm{hm}$, though news receipts clearly are present too. The explanation for this is that the recipient who uses Right is not necessarily acknowledging the information as new, but the expression of the RELATIONSHIP OF DEPENDENCY between the utterances in advancing the epistemic store is what is new in the current context of the talk. In excerpt (3), for example, the second Right in line 2044 responds to the dietician's talking about a high fat choice, and then exemplifying it with a contrast: biscuits and what's a better choice to have. It may or may not be the case that the client knows that biscuits are high in fats. An $\mathrm{Mm} \mathrm{hm}$ in this environment would be noncommittal about marking the prior talk in some special way: As Jefferson 1984 put it, Mm $\mathrm{hm}$ shows PASSIVE RECIPIENCY.

In the following sections, examples of Rights responding to various epistemic dependency relationships that progress the epistemic store will be discussed, first where they occur in informing sequences, and second where they occur in advicegiving sequences. Note that both of these types of sequence are ones in which a speaker is using "facts" to achieve some change in the recipient - either in recipient's knowledge or in behavior. 
In excerpt (4), the main focus is on the Right in line 255, but the one in line 259 will also be discussed. This extract is from early in the consultation, and the dietician is setting out the agenda for the next phase, in which she will gather information about the client's dietary habits. She introduces this by a formulation of the goals: What I'll do now is just have a look at what you sort of tend to eat, during the day and when you're at home, or when you're at work of course.

(4) JD36:CT13:6'37":248

\begin{tabular}{|c|c|c|}
\hline $\begin{array}{l}248 \\
249\end{array}$ & D: & $\begin{array}{l}>\uparrow \uparrow \text { 'kay whad u'll } \downarrow_{\text {do now, }}=\text { 's j'ss have a } \\
\text { *look- at-* }(.) \text { what you s'v tend to eat-, }\end{array}$ \\
\hline 250 & & during the da:y;=en wh'n yuh'd $\uparrow$ ho:me; $=\downarrow$ er \\
\hline 51 & & when yer et $\uparrow_{\text {wo:rk }}=$ 'f cou:rse? $[\cdot$ hhhh $]=$ \\
\hline 252 & $\mathrm{Cl}:$ & {$[\mathrm{Mm} \mathrm{hm}]$,} \\
\hline 253 & D: & 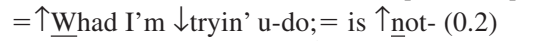 \\
\hline 54 & & $\downarrow$ necessar'ly wha'you ate $\uparrow$ yestuhda:yi b't \\
\hline 55 & & j' s tuh g]edda picture ev: $\cdot$ hh $\uparrow_{\underline{i n}} \downarrow \downarrow_{\text {gen'ral; }}=$ \\
\hline 56 & $\mathrm{Cl}: \rightarrow$ & [ Righ';] \\
\hline 257 & D: & $=\uparrow \underline{\text { what }}-\mathrm{d} \downarrow$ be yuh u: ${ }^{\prime}$ 'al sordev inta:hke; \\
\hline 259 & $\mathrm{Cl}: \rightarrow$ & {$\left[{ }^{\circ} \mathrm{Mm} \mathrm{hm},{ }^{\circ}\right]$} \\
\hline 260 & D: & $=[\underline{\text { starding }}]$ with break-f'st, an' $\uparrow_{\text {going }}=$ \\
\hline 51 & $\mathrm{Cl}$ : & {$[\bar{R}: i: g h t]$,} \\
\hline 262 & D: & $=[$ throu:]:gh? $(.) \mathrm{hmh} \cdot \mathrm{nhh}$ \\
\hline 263 & Cl: & {$[\mathrm{Mm} \mathrm{hm}]$,} \\
\hline 264 & & $(2.0)-1$ \\
\hline $\begin{array}{l}265 \\
266\end{array}$ & $\mathrm{Cl}:$ & $\begin{array}{l}\text { Uh::m; so:. (.) breakf'st w'd norm'ly bi } \\
\text { ce:real }\end{array}$ \\
\hline
\end{tabular}

The dietician is launching a new phase in the consultation: Okay, what I'll do now. She does this by projecting the main activity of this phase, which is to gather information about what the client eats; and to do this, she lists the scope of this - during the day, when you're at home, and when you're at work of course. This receives an $\mathrm{Mm} \mathrm{hm}$ from the client. This continuer is acknowledging a list: There is no particular dependency between the parts of the list, apart from reflecting a temporal sequence (an 'and then' or 'and next' kind of relationship), so no Right. ${ }^{8}$ The dietician goes on to restrict the scope of her projected information gathering, by stating that it is not what he ate the previous day that is the focus of her interest. This receives a Right, which acknowledges a kind of 'I'll do $\mathrm{X}$, but not $\mathrm{Y}^{\prime}$. In other words, in informing him of the planned agenda for their meeting, at this point she is saying what she is NOT doing (Y), after having said what she Is doing (X), where $\mathrm{Y}$ is some kind of constraint on the scope of $\mathrm{X}$. Client's Right claims a recognition of the epistemic dependency between these two pieces of information. It comes a little after a point of grammatical completion in line 254, as the dietician has hearably begun a contrastive continuation to what she is not going to do (but just). Note that it is highly unlikely that this is an epistemic confirmation, as this is the first mention in the consultation of her 
goals for this phase, so he would not have known what would come next. It is also very unlikely to be a change-of-activity token, as she has just started a continuation to express the contrast.

She then goes on to produce the contrast, which is the type of action after which a Right is regularly found. What comes, though, is $\mathrm{Mm} \mathrm{hm} .^{9}$ The reason is that lines 254-5/257-8 are a reiteration of lines 248-251: She wants to get a picture of his usual sort of intake; this is very similar to have a look at what you tend to eat during the day. As this has already been established - it is not a newly stated dependency relation - a simple continuer is found. The $\mathrm{Mm} \mathrm{hm}$ comes just after a possible completion point after intake, but she increments her turn with two prepositional phrases, the second one a time adverbial. The pitch on the final word of the time adverbial rises and falls strongly and is lengthened considerably, so there is full intonational, as well as grammatical and pragmatic, completion here (Ford \& Thompson 1996). It appears the client takes this as sequence-final, proposing a moving out of this preliminary and into the information gathering, and he produces a change-of-activity Right. However, the dietician increments yet further by proposing a temporal sequencing of the information she is seeking. Note that the client's Right starts simultaneously with starting, the first word of this continuation, so he had no audible evidence that she will continue. After her increment, and a further continuer $\mathrm{Mm} \mathrm{hm}$, he does indeed launch into the next (long) phase of the consultation, by beginning with what he eats for breakfast.

An important question is what is going on when a strong epistemic dependency is expressed and no Rights are found. Extract (5) is from a sequence in which the dietician is explaining triglycerides to the client. He has said that he doesn't know much about this dietary fat.

(5a) JD91:974

\begin{tabular}{|c|c|c|}
\hline $\begin{array}{l}974 \\
975\end{array}$ & D: & 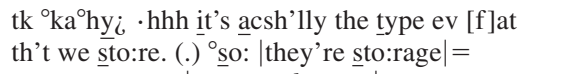 \\
\hline & $\mathrm{Cl}$ : & $\mid \_$nods- - \\
\hline 976 & $\begin{array}{l}\mathrm{D}: \\
\mathrm{Cl}:\end{array}$ & $=\underline{\text { fa:ts. }}{ }^{\circ} \cdot$ hhhh uh- it's also:- $\mid$ triglycerides $=$ \\
\hline 977 & D: & $\begin{array}{l}=\text { are prehsent in } \uparrow \text { foo: } \mathrm{d} \uparrow ;=\text { they're thuh fats } \\
\text { that we ea:t in foo: } \mathrm{d} \text { as [we:ll. }\end{array}$ \\
\hline 979 & $\mathrm{Cl}$ : & [R:igh'.] \\
\hline 980 & & (.) \\
\hline 981 & D: & - $\mathrm{pt}^{\circ}{ }^{\circ} \mathrm{kayh}_{\dot{i}}{ }^{\circ} \cdot$ hhh So when we eat a hi:gh fat \\
\hline 982 & $C l:$ & $\uparrow_{\text {fo:o: }} \mathrm{d}_{i} \mid \cdot$ hhh u:hm- $\mid(0.3)$ a lodev it is $=$ \\
\hline 983 & D: & 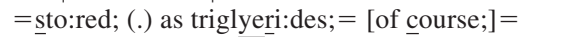 \\
\hline 984 & $\mathrm{Cl}$ : & {$[\mathrm{M} \overline{\mathrm{m} \mathrm{h} \mathrm{m},]}$} \\
\hline 985 & D: & $=$ as excess: body fa:ht, $\cdot$ hhh which is in the body \\
\hline & & . hhh $(.)^{\circ}$ um- $^{-}{ }^{\circ}($.$) course we don’ wanna have$ \\
\hline 98 & & that level too high $\uparrow$ e:e \\
\hline & $C l:$ & $\mid-$ nod $-\left.\right|^{-}$ \\
\hline & D: & [bicos if $]$ we're storin lotsev extra fat, $=$ then $=$ \\
\hline & $\mathrm{Cl}:$ & {$[\mathrm{Mm} ; \mathrm{hm}$} \\
\hline
\end{tabular}




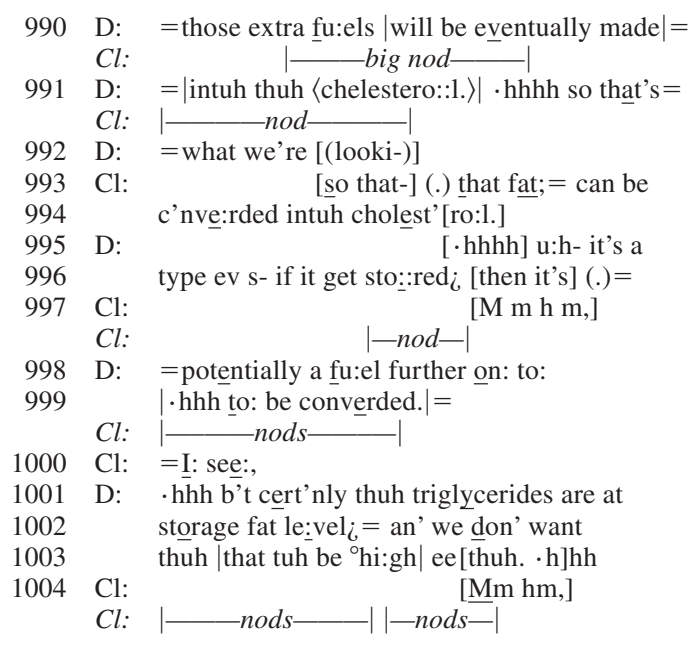

At the start of this extract, the dietician is starting her explanation of triglycerides. The client's Right in line 979 is acknowledging the relationship between, on the one hand, that triglycerides are storage fat fats, and on the other that they are present in food: The dependency is between the two loci of triglycerides. She goes on to say when we eat a high fat food, a lot of it is stored as triglycerides. The client produces an $\mathrm{Mm} \mathrm{hm}$ here, although there is a dependency relationship of consequence here. However, it is unlikely that his epistemic store has progressed, as what the dietician has said is easily retrievable from what she had said before the Right: Essentially, she is saying nothing new here. A moment later she says course we don't wanna have that level too high either. This is knowledge he has already displayed having. Back in the first minutes of the consultation he had said why he had come to the hospital:

(5b) JD91:17

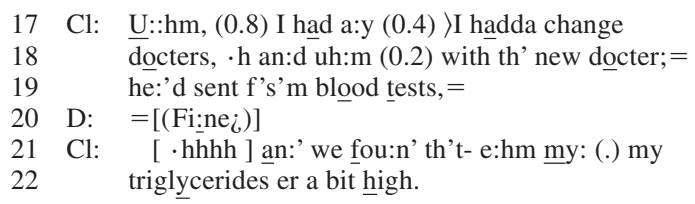

The $M m ~ h m$ in line 984 of (5a) is produced in preference to a Right because nothing has been added to his epistemic store. She goes on to give a reason for not wanting triglyceride levels to be high: because if we're storing lots of extra fat, then those extra fuels will be eventually made into cholesterol, a classic environment for a Right, with a dependency of reason being expressed. However, he follows this not with a response token but with a request for confirmation of what she had said: so that fat can be converted into cholesterol. She rephrases what she had said: if it gets stored, then it's potentially a fuel further on to be 
converted. After the if-clause, there is a continuer $\mathrm{Mm} \mathrm{hm}$, in a classic position after the first of two dependent clauses, and on completion of this rephrasing, he says I see, a newsmarker (i.e., an indication that this is news to him). Her last utterance in this extract is again a reiteration of something old, that it is undesirable to have high triglycerides stored. As this is old news, a continuer $\mathrm{Mm} \mathrm{hm}$ is to be expected, and it does occur.

The next section will continue to explore epistemic dependency marking Rights, but in the environment of advice-giving rather than informing sequences.

\section{A D VICE SEQUENCE RIGHTS}

In example (6a), which is from the closing stages of the consultation, the dietician advises the client not to go for your regular soft drinks (lines 1831-2) and then provides a reason for the advice, because they're going to be loaded with sugar anyway (lines 1832-3).

(6a) JD61/RA6-89a:40'18":1823

\begin{tabular}{|c|c|c|}
\hline 1823 & D: & {$[\cdot$ hhhhh] but- em- then looking et- $()=$.} \\
\hline 1824 & $\mathrm{Cl}:$ & {$[\mathrm{Mm} \mathrm{hm}]$,} \\
\hline 1825 & D: & $={ }^{\circ}$ yihknow $^{\circ} ;(0.2)$ looking aftuh yuhse $(\mathrm{h}) 1 \mathrm{fh}$ \\
\hline 1826 & & [es we $($ h) $11 ;]=[$ not- maki]ng yuh $=$ \\
\hline 1827 & $\mathrm{Cl}:$ & [(That's- ev ] [ course). $]$ \\
\hline 1828 & D: & $=$ triglyceri [:des: u-bi- ] hi:gher; \\
\hline 1829 & $\mathrm{Cl}$ : & [That's righ'; $]$ \\
\hline 1830 & D: & {$[\cdot \underline{\mathrm{HHHH}}-] \mathrm{HH}$ u:hm; (.) p'haps looking et anothuh $=$} \\
\hline 1831 & $\mathrm{Cl}:$ & {$[\overline{\mathrm{Mm} \mathrm{hm}}]$,} \\
\hline 1832 & D: & $=$ dri: $\underline{\text { nk. }}\rangle \underline{\mathrm{OTH}}$ Tuh drinks; thee: um u-wouldn' tend \\
\hline 1833 & & uh go; $=$ fer yer regulah soft dri:nks ${ }_{i}=$ c's theh \\
\hline 1834 & & genna be (.) loaded with suger any $\left[\right.$ wa: $\left.y_{i} \cdot \bar{h}\right] \mathrm{hh}=$ \\
\hline 1835 & $\mathrm{Cl}: \quad \rightarrow$ & [R:i:gh' $\left.{ }_{i}\right]$ \\
\hline 1836 & D: & $=$ sordev difeading (.) that pu:r[pose $i \cdot h] \mathrm{hh}=$ \\
\hline 1837 & $\mathrm{Cl}:$ & {$[\mathrm{Mm} \mathrm{hm}]$,} \\
\hline 1838 & D: & $=\mathrm{u}: \mathrm{hm} ;($.$) uhlthough et's still bedduh th'n$ \\
\hline 1839 & & thih $\uparrow$ alcoho: 1 \\
\hline
\end{tabular}

The Right in line 1835 acknowledges a reason for the advice not to drink regular soft drinks. It might be argued that this is an epistemic confirmation, because by this stage in the conversation he would know that sugars are bad for his triglycerides - the point had been made several times. However, a few minutes earlier there had been a reference to soft drinks:

(6b) JD61a:1708

\begin{tabular}{|c|c|c|}
\hline 1708 & D: & c'n yuh think of uh wa:y; = th't yuh could- (.) \\
\hline 1709 & & ged aroun' it $i=[-]$ or $\uparrow$ seggestions ev how yuh \\
\hline 1710 & & could- ${ }^{-} \cdot \operatorname{mnhhhh}(0.2)$ how d'yuh think y'll \\
\hline 1711 & & approa:ch et. \\
\hline 1712 & $\mathrm{Cl}:$ & $\cdot \mathrm{pthh} h[\mathrm{hhhh}$ \\
\hline 1713 & D: & [ jes' tuh be practic'l. hnhhhhhh \\
\hline 1714 & $\mathrm{Cl}$ : & $(($ soft, fortis, rasping throat clearing $))$ \\
\hline 1715 & & $(0.4)$ \\
\hline
\end{tabular}




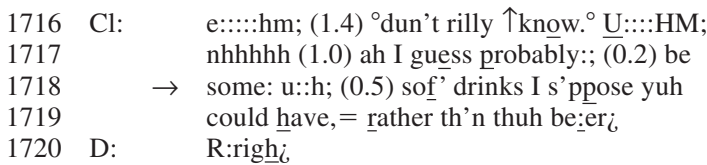

In this sequence, the client had himself suggested soft drinks as an alternative to beer, and this is one of the cases where it is the dietician who responds to the client with a Right. ${ }^{10}$ His suggestion of having soft drinks rather than beer is, first, an expression of alternativity, which is the complex relationship. It also happens to refer to the "macro-topic" of reducing his beer consumption, so in that respect is part of a larger, complex activity. We can now see that the dietician's Right here was not confirming the correctness of his suggestion, as she does not in fact think he is right to make this proposal, and it would be strange indeed for her to be telling him that he is right to be doing something that is not beneficial to his dietary practices. The second point is the converse of the same point: The client had proposed soft drinks in line 1718, and an acknowledgment that he had proposed something that he knew to be bad for him in line 1835 would similarly be strange. The more plausible explanation is that he is acknowledging the reason for advice (i.e., a TCU that is dependent on an immediately preceding TCU), and in doing so he is claiming epistemic progression - he has now made a connection that he had not made before.

As a final example, (7) shows how the epistemic dependency relations acknowledged by Right can work across considerable discourse distance. In this phase, the dietician is advising him on ways to improve his dietary intake. For a few minutes they discuss fish. This phase begins as follows:

(7a) JD45:1540

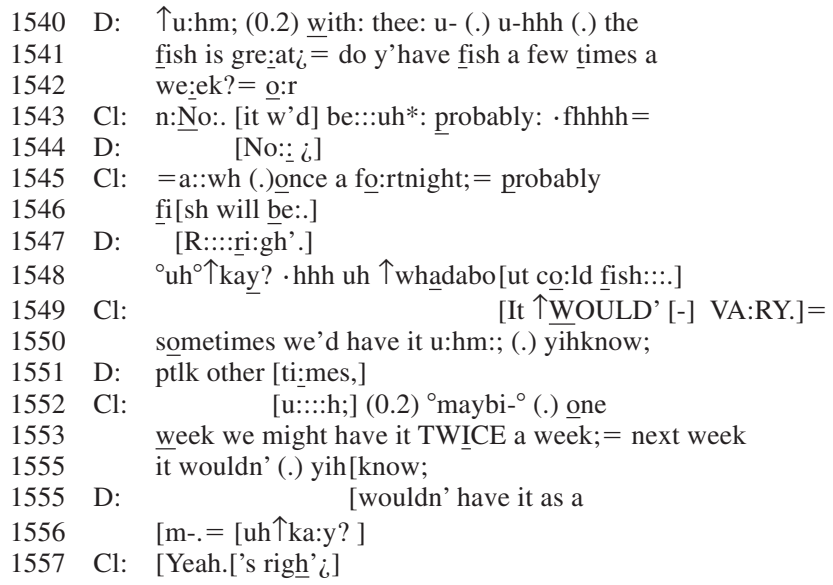

She asks how often he eats fish, with a candidate answer of a few times a week, which turns out to be wrong: he has fish once a fortnight, probably. ${ }^{11}$ They then 
establish the approximate frequency with which he eats cold fish. For more than a minute following this sequence they discuss fish: She makes suggestions about increasing his fish intake - canned salmon and tuna with a salad, or in a casserole; she recommends fish as being good for reducing cholesterols and triglycerides - if they are grilled or steamed; if canned, they should be canned in water, not oil; they can go on a sandwich. Then comes this sequence:

(7b) JD45:1601

\begin{tabular}{|c|c|c|}
\hline 1601 & D: & [they're other suggestions ev [things, ] $\cdot \mathrm{hhh}$ \\
\hline 1602 & $\mathrm{Cl}:$ & ['s right.] \\
\hline 1603 & D: & [an' a way ev gedding a bidev ${ }^{\circ}$ extra fish: ${ }^{\circ}$; \\
\hline 1604 & $\mathrm{Cl}:$ & {$\left[{ }^{\circ} \mathrm{Mm} \overline{\mathrm{hm}},{ }^{\circ}\right.$} \\
\hline 1605 & D: & (.) through them:; $\cdot$ hh [to-] (.)] u:hm:; (.)= \\
\hline 1606 & $\mathrm{Cl}$ : & $\left.[\mathrm{Mm}] \mathrm{hm}_{i}\right]$ \\
\hline 1607 & D: & $=$ if possible; it's great tuh have $\rangle$ y'know \langle \\
\hline 508 & & tw:ice a week $\underline{i}_{i}{ }^{\circ}{ }^{\circ}$ three times [a week i] $\mathrm{f}=$ \\
\hline 1609 & $\mathrm{Cl}:$ & {$[\overline{\mathrm{Mm}} \mathrm{hm}]$,} \\
\hline 10 & D: & $=$ possible: $i$ \\
\hline 610 & $\mathrm{Cl}: \quad \rightarrow$ & Ri:gh'. \\
\hline
\end{tabular}

It's great to have, you know, twice a week, or three times a week if possible comes with no apparent local epistemic dependency. This looks like a stand-alone TCU, making a bald suggestion about the frequency of his fish intake. I would argue, though, that the dependency he is acknowledging is back over one minute to her question and his answer about how often he eats fish (lines 1541-57). The advance of his epistemic store is that he is now being told he should eat fish more often than he reported doing a minute or so earlier.

C O N CLUS I O N

Rights are found frequently in information- and advice-giving sequences in Australian and British English. These Rights are epistemic dependency tokens, which progress the shared epistemic store, extending the common ground between speakers. They are claims on the part of the recipient that he or she recognizes the prior unit of talk as being dependent on some other talk, and that these are part of a complex activity such as an extended informing or advice-giving sequence. Such activities are rich grounds for presenting information. In the dietetic data used for this study, the informing sequences widen the pool of knowledge the recipient has, and the advice sequences provide the recipient with the kind of information that will help him to change his lifestyle (specifically his nutrition) for the better. These are not the only environments in which epistemic progression Rights are found. They can occur, for example, in narratives, but then when some complex relationship of dependency is being expressed, for example a reason for something happening; or they can occur in assessment sequences, particularly when a second assessment (by the same speaker) qualifies a first one. So Right is not constrained so much by the type of activity in which it occurs, but is far more common in activities that involve 
a lot of information transfer. This is so because it claims recognition that epistemic progress has been made through two interdependent elements of talk. There is not so much a change-of-state in the sense of now knowing something that was not known before, as a change-in-understanding in the sense of recognizing how two elements within a complex activity advance the understanding of the wider activity.

The response token Right is, in a similar way to related receipt tokens such as $M m$ hm, Uh huh, Yeah, Mm, and Oh, complex and multi-functional. Apart from the uses noted in this article, others have been found, and an article on these is in preparation. Here there has been an attempt to provide an initial, but fairly detailed, characterization of one common use of this token. This type of Right is used to mark the talk to which it is oriented as advancing the epistemic store of the Right producer. This Right appears to have largely lost its basic meaning of 'correct', and to be used as a token marking agnate connections between two prior units of talk. However, some trace of the meaning of 'correct' is still present in that it responds to informing types of turns, so it is a kind of epistemic token, related to (but different from) newsmarkers or news tokens (such as $\mathrm{Oh}$ ).

In this sense, a particular distinctiveness of Right is that it is not only acknowledging a turn but is also claiming that its producer understands the relevance of this utterance in relation to something prior. This makes Right different from classic continuers such as $\mathrm{Mm} \mathrm{hm}$ or $\mathrm{Uh} h u h$, which are neutral beyond asking for more from the other speaker, and from acknowledgment tokens such as Yeah or $\mathrm{Mm}$, which are marking receipt of the previous turn (and no others) in various ways. It is also different from the change-of-state token $\mathrm{Oh}$ or newsmarkers, which are marking the prior turn (and not others) as specifically being new information to the recipient. More could be said about some features of these Rights, notably the effect of prosody in particular intonation. Nevertheless, there is strong evidence that this and related types of Right are consistently used to mark connections across TCUs within a larger activity.

Two other uses of Right referred to in this essay are (i) as an epistemic confirmation token, in which the semantic link to Right in the sense of 'correct' is quite salient, in that a speaker uses this token to confirm that some proposition by the prior speaker is indeed correct, or that the knowledge displayed in the prior turn by another speaker is shared by the Right producer, and this appears to be the dominant use of the token in North American English. The other use of Right as a response token is as a variant (or a truncated version) of Alright, a token related to Okay as a 'change-of-activity' token; this Right proposes moving out of the current activity into another and is found regularly at the end of extended sequences, or as a pre-closing token in the closings of conversations.

Right as a marker of epistemic progression is in a sense the opposite of an epistemic confirmation marker: Where a relationship has been established, or is obvious (i.e., when something is already known by the recipient), Right is avoided, and instead a continuer $\mathrm{Mm} \mathrm{hm}$ or acknowledgment token Yeah is used. Episte- 
mic progression marked by Right is not the result of any connections, but of connections that have not been made before in the talk. If points of connectivity have been established previously in the interaction, and thus are not building the epistemic store, they are not receipted with a Right. What these Rights do is acknowledge the juxtaposition of the ideas for some current purpose in the talk: This is what is new.

\section{NOTES}

${ }^{1}$ This article has been evolving for nearly ten years, and I wish to thank numerous members of a range of audiences for their stimulating questions. I also wish to thank four anonymous reviewers whose penetrating questions led to two fairly radical rethinks of the arguments and organization. I would particularly like to thank Keith Abbott, who was in the audience for what I hope was the last oral presentation of this paper. He provided extensive written feedback and really put me on the track of epistemic progression marking as being the best characterization of this response token.

${ }^{2}$ By saying that they do not add to the development of topic, I am of course not claiming that they have no influence on the trajectory of the topic, but that in and of themselves, they do not contribute to the topic in the way that most substantial turns do.

${ }^{3}$ For a more comprehensive survey of these response tokens, see Gardner 2001, chapter 2.

${ }^{4}$ One reason there are fewer Rights from U.S. data is that this token appears to be less common in U.S. talk. Several thousand lines of transcription were trawled to find these 50 or so cases.

${ }^{5}$ Thanks to Chuck Goodwin for permission to use this extract from Chinese Dinner.

${ }^{6}$ The original line numbering from the full transcript is retained so that readers can see at a glance approximately how far into the interview the fragment is, while the figures $44^{\prime} 07^{\text {" }}$ indicate the number of minutes and seconds into the interview. This is helpful in some of the fragments presented, as links between current and earlier talk are sometimes discussed. The full consultation lasted just over 47 minutes, and the full transcription is nearly 2200 lines.

${ }^{7}$ There are, however, at least three Rights in Maynard 2003 that do appear to be epistemic dependency markers. For example, on p. 190, in an American data extract in which a patient has just heard from a counselor that he is HIV positive, the councilor says they did the elisha test?, which gets an $\mathrm{Mm} \mathrm{hm}$, and next says and they backed it up with another test called the western blot. The client responds to this naming of the second test with Right. This is in itself not the bad news, which had been given a few moments earlier, but something that is adding the client's epistemic store about the way in which the diagnosis was confirmed. There is also a dependency: between the first test, mentioned immediately prior to this exchange, and the second, the Western blot. Thanks to Doug Maynard for confirming that these are American data.

${ }^{8}$ It is important to note that there may be strong differences between individual speakers, as Jefferson 1984 argued with reference to $\mathrm{Mm} \mathrm{hm}$ and Yeah. She found that some speakers used and distinguished both tokens, while others overwhelmingly used only Yeah. However, those who used only Yeah made distinctions through prosody that were similar to the distinctions users of both tokens made. Indeed, she was surprised to find how systematic speakers were, saying "I balked at there being order at THIS point. Even now ... when the phenomenon turns up again ... I am surprised anew. Look at that! They really do it!" (1984:17). So it is not that speakers are not systematic in their use of response tokens, but that they are systematic in different ways - at least to some degree. Guthrie 1997 also addresses the question of differences in the use of response tokens between speakers. In her case, she compared Okay and $\mathrm{Mm} \mathrm{hm}$ used by students in academic advising sessions. She asks, "Are these two acknowledgement tokens ... in fact interchangeable?" given the inconsistencies she found in their use. She goes on to argue that "there is indeed a difference, at least for some speakers." So she, like Jefferson, is saying that not all speakers differentiate between tokens (though qualified by "at least," suggesting she is not sure). She does, though, also say that her results support the view that "there is, in fact systematicity in the smallest elements of conversation" (399). In addition, her analysis was principally in terms of use of the two tokens in terms of the completedness of the prior TCU (i.e., driven by the turn-taking organization), rather than in terms of the actions accomplished by the tokens (i.e., driven by an action analysis). 
In terms of the Right in excerpt (4), for some speakers the strength of the dependencies in this list may have been sufficient for a Right to be produced. Indeed, to my ears Right would not sound inappropriate here. However, conceding this point does not negate the fact that such Rights are found in environments of epistemic dependency, and the stronger the dependency, particularly in terms of logical dependencies such as contrast, reason, or purpose, the greater the likelihood of Right being used, as in what follows in this sequence.

${ }^{9}$ One task that needed to be done in this project was to look at environments in which epistemic dependency Rights might be expected to occur but did not. More than 30 such environments were located and analyzed in the core dietetic consultation data. A detailed discussion of these cases is not possible here, but two examples should suffice to illustrate that accounts can be given in almost all cases to explain why Right was not chosen. Sometimes it is simply that some other token or action fits the environment, for example an agreement token Sure, or a clarification question. Here is one where the dietician might have chosen Right but did not. The dietician has asked the client to say what he knows about cholesterol:

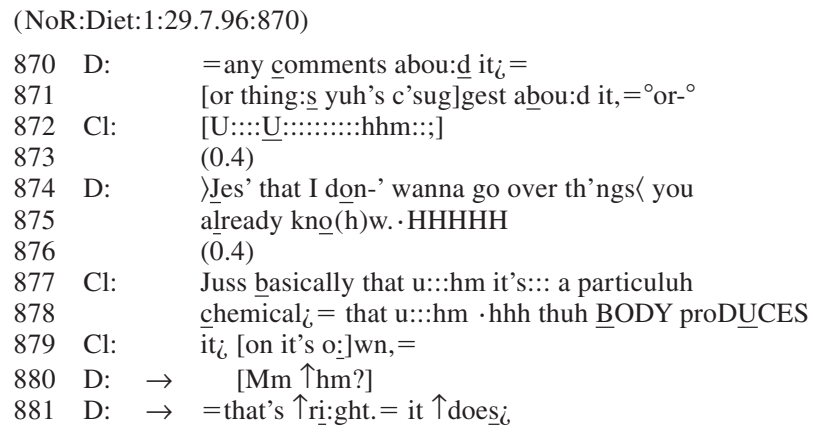

The client identifies cholesterol as a chemical and then specifies one of its characteristics, that it is produced by the body. This is in many ways similar to ex. (3), where the dietician showed him an information sheet, identified it, and specified its contents. The client is ostensibly engaged in an informing sequence, though of course this is more about displaying his prior knowledge. The dietician is the expert; she knows about cholesterol. Her epistemic store is not being progressed, so she produces an $\mathrm{Mm} \mathrm{hm}$, followed by a strong epistemic confirmation, underlining her position as expert.

A second example is from near the end of the dietician's own explanation of cholesterol a few minutes later:

(NoR:Diet:1:29.7.96:939)

939 D: $\quad$. hhh so that's why we recemmen:d fer all

$940 \quad$ Aus $\uparrow$ tralians $\uparrow ;=$ to have a- $\cdot \overline{\text { hh }}$ h a healthy lo:w

941 fat di:et; [ hhhhh] so that we're not=

$942 \mathrm{Cl}: \quad[\mathrm{Mm} \mathrm{hm}$,

943 D: = provi:ding lots ev extra fa:t-; (.) $\cdot$ hhh that

944 then gets made into chelest'rol.

945 Cl: Rī $\quad$ :gh'.

946 D: [So that's how we c'n try an' stop- (0.2)

947 ou'sel's from making excess amounts if we do::.

$948 \quad[\cdot$ hhhhh $]$ an' par $\uparrow$ tic'ly [-] animal fats; $=$

$949 \mathrm{Cl}: \quad[\mathrm{Mm} \mathrm{hm}$,

950 D: = will drive that reahction: (.) further;

$951 \quad[\cdot \mathrm{hhhh} \overline{\mathrm{h}}$ so] uh's: saturaded animal fa:ts; $=$

$952 \mathrm{Cl}: \rightarrow\left[^{\circ} \mathrm{I}[-]\right.$ see..$\left.^{\circ}\right]$

In 946 onward, the dietician is providing a complex packet of information about the relationship between fatty diets, particularly those containing animal fats, and the body producing excess choles- 
terol: a classic Right environment. However, the client has chosen here a newsmarker. That is, he is not marking this as adding to his epistemic store, but more strongly is marking this as something he has just learned. Examples where $\mathrm{Mm} \mathrm{hm}$ occurs in a potential Right position are discussed in the main body of the text.

${ }^{10}$ Dietician's Rights occur far less frequently in this consultation than client's Rights. This is not surprising, given that the dietician, as expert, is providing the client with most of the advice and information. In the phase where the client provides the dietician with a lot of new information, the information-gathering phase, he tells her in detail of his quotidian dietary habits. In this environment, the dietician mostly uses $\mathrm{Mm} \mathrm{hm}$ and Okay and assessments such as Great to receipt his information, as in the following fragment:

(NoR:Diet:1:29.7.96:266)

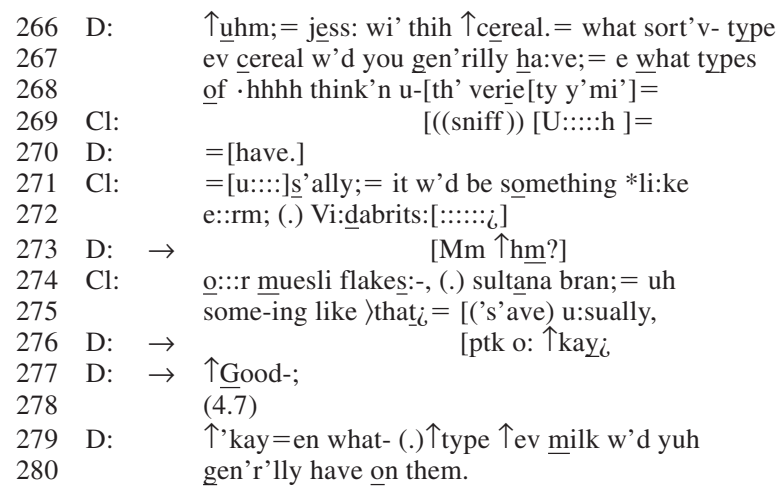

Dietician asks a question about breakfast cereals, and the client gives an answer that includes examples of the food. During his listing she produces an $\mathrm{Mm} \mathrm{hm}$, a continuer that is recognizing the incompletion of his list of examples, and when he finishes, she does an Okay, followed by a positive assessment Good. The lack of Rights in this phase can be explained by the nature of the activity: She has an "agenda" of questions that are written down on a sheet of paper. Similar to other medical consultations with routine question-answer sequences, the completion of each sequence is regularly marked with a third position Okay, which indicates readiness to move on to the next agenda question (e.g. Boyd \& Heritage 2006:170). In this case, there is an additional Good, which probably is the dietician expressing a positive judgment of the client's choice. The reason Rights are so unusual in this environment is that the activity is an additive series of simple questions and answers, and not an extended complex activity such as an explanation or extended advice. Right occurs where extra work needs to be done to connect dependent elements of such complex elements.

${ }^{11}$ The Right produced by the dietician here is a somewhat different one from the epistemic dependency Rights discussed in this article, though the epistemic dependency is apparent. A major difference is that this Right comes in third, not second position in the sequence. Nevertheless, the dependency is apparent. She has asked a question, and into that question she has built a candidate answer. The answer reveals the presupposition to be wrong. Thus her epistemic store has progressed. The answer is, of course, news to the dietician, and an $\mathrm{Oh}$ or a newsmarker would fit. However, as Atkinson 1992 and Clayman 1992 have shown for courtroom and news interview settings, neutrality on the part of the institutional representative is an institutional requirement. Right shows greater neutrality than $O h$ or Really.

\section{REFERENCES}

Atkinson, J. Maxwell (1992). Displaying neutrality: Formal aspects of informal court proceedings. In Drew \& Heritage (eds.), 199-211.

Beach, Wayne (1993). Transitional regularities for 'casual' "Okay" usages. Journal of Pragmatics $19: 325-52$. 
Boyd, Elizabeth, \& Heritage, John (2006). Taking the patient's medical history: Questioning during comprehensive history taking. In John Heritage \& Doug Maynard (eds.), Communication in medical care: Interactions between primary care physicians and patients, 151-84. Cambridge: Cambridge University Press.

Bublitz, Wolfram (1989). Ausdrücke des Kenntnisnehmens (Hörersignale) oder des Stellungnehmens (Redebeiträge): yes und verwandte Formen. Folia Linguistica 23:67-104.

Clancy, Patricia; Thompson, Sandra; Suzuki, Ryoko; \& Tao, Hongyin (1996). The conversational use of reactive tokens in English, Japanese, and Mandarin. Journal of Pragmatics 26:355-87.

Clayman, Steven (1992). Footing in the achievement of neutrality: The case of news-interview discourse. In Drew \& Heritage (eds.), 163-98.

Drummond, Kent, \& Hopper, Robert (1993). Back channels revisited: Acknowledgement tokens and speakership incipiency. Research on Language and Social Interaction 26:157-77.

Ford, Cecilia, \& Thompson, Sandra (1996). Interactional units in conversation: Syntactic, intonational, and pragmatic resources for the management of turns. In Elinor Ochs, Emanuel Schegloff \& Sandra Thompson (eds.), Interaction and grammar, 134-84. Cambridge: Cambridge University Press.

Gardner, Rod (1997). The conversation object mm: A weak and variable acknowledging token. Research on Language and Social Interaction 30:131-56.

(2001). When listeners talk: Response tokens and recipient stance. Amsterdam: Benjamins.

Goodwin, Charles (1979). The interactive construction of a sentence in natural conversation. In George Psathas (ed.), Everyday language: Studies in ethnomethodology, 97-121. New York: Irvington.

Guthrie, Anna (1997). On the systematic deployment of Okay and Mmhmm in academic advising sessions. Pragmatics 7:397-415.

Heritage, John (1984). A change-of-state token and aspects of its sequential placement. In J. Maxwell Atkinson \& John Heritage (eds.), Structures of social action, 299-347. Cambridge: Cambridge University Press.

(1998). Oh-prefaced responses to inquiry. Language in Society 27:291-334.

(2002). Oh-prefaced responses to assessments. In Cecilia E. Ford, Barbara A. Fox \& Sandra A. Thompson (eds.), The language of turn and sequence, 81-122. Oxford: Oxford University Press.

, \& Raymond, Geoffrey (2005). The terms of agreement: Indexing epistemic authority and subordination in talk-in-interaction. Social Psychology Quarterly 68:15-38.

, \& Sefi, Sue (1992). Dilemmas of advice: Aspects of the delivery and reception of advice in interactions between health visitors and first-time mothers. In Paul Drew \& John Heritage (eds.), Talk at work: Interaction in institutional settings, 359-417. Cambridge: Cambridge University Press.

Jefferson, Gail (1983). Two explorations of the organization of overlapping talk in conversation: Notes on some orderliness in overlap onset. Tilburg Papers in Language and Literature, No. 28. Tilburg: Tilburg University.

(1984). Notes on a systematic deployment of the acknowledgement tokens 'yeah' and 'mm hm'. Papers in Linguistics 17:197-216.

(1993). Caveat speaker: Preliminary notes on recipient topic-shift implicature. Research on Language and Social Interaction 26:1-30.

(2002). Is "no" an acknowledgment token? Comparing American and British uses of (+)/

(-) tokens. Journal of Pragmatics 34:1345-83.

Maschler, Yael (2002). On the grammaticization of ke'ilu 'like', lit. 'as if', in Hebrew talk-ininteraction. Language in Society 31:243-76.

Maynard, Doug (1997). How to tell patients bad news: The strategy of 'forecasting.' Cleveland Clinic Journal of Medicine 64:181-82.

(2003). Bad news, good news. Conversational order in everyday talk and clinical settings. Chicago: University of Chicago Press.

McCarthy, Michael (2003). Talking back: "Small" interactional response tokens in everyday conversation. Research on Language and Social Interaction 36:33-63.

Müller, Frank-Ernst (1996). Affiliating and disaffiliating with continuers: Prosodic aspects of recipiency. In Elizabeth Couper-Kuhlen and Margret Selting (eds.), Prosody in conversation: Interactional studies, 131-76. Cambridge: Cambridge University Press. 
Schegloff, Emanuel (1982) Discourse as an interactional achievement: Some uses of 'uh huh' and other things that come between sentences. In Deborah Tannen (ed.), Analyzing discourse: Text and talk, 71-93. Washington: Georgetown University Press.

(1993) Reflections on quantification in the study of conversation. Research on Language and Social Interaction 26:99-128.

(2007) Sequence organization in interaction: A primer in conversation analysis, Vol. 1. Cambridge: Cambridge University Press.

, \& Sacks, Harvey (1973). Opening up closings. Semiotica 8:289-327.

Sorjonen, Marja-Leena (1996). On repeats and responses in Finnish conversations. In Elinor Ochs, Emanuel Schegloff \& Sandra Thompson (eds.), Interaction and grammar, 277-327. Cambridge: Cambridge University Press.

Stenström, Anna-Brita (1987). Carry-on signals in English conversation. In W. Meijs (ed.), Corpus linguistics and beyond, 87-119. Amsterdam: Rodopi.

Tapsell, Linda (1997). Client-centred practice: An interactional case study of dietary counselling. Health 1:107-20.

Traugott, Elizabeth, \& Dasher, Richard (2002). Regularity in semantic change. Cambridge: Cambridge University Press.

Turner, Kimberley (1999). Functional variation of Okay/Alright usage in spoken discourse. Special Project, University of New South Wales, Semester 2, 1999.

(Received 29 June 2005; revision received 28 February 2006; accepted 5 March 2006; final revision received 18 September 2006) 